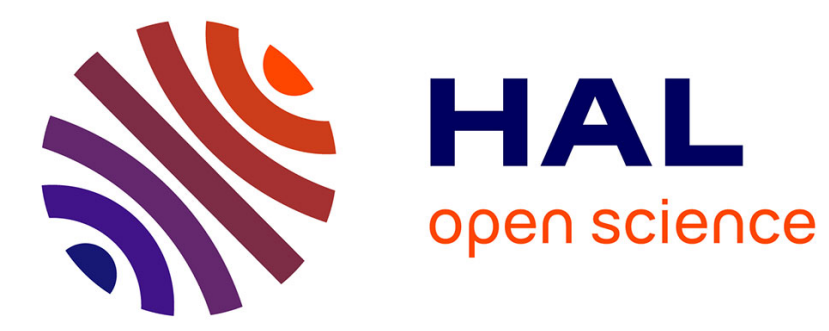

\title{
Salmonella serotypes in reptiles and humans, French Guiana
}

Noellie Gay, Simon Le Hello, François-Xavier Weill, Benoit de Thoisy, Franck Berger

\section{- To cite this version:}

Noellie Gay, Simon Le Hello, François-Xavier Weill, Benoit de Thoisy, Franck Berger. Salmonella serotypes in reptiles and humans, French Guiana. Veterinary Microbiology, 2014, 170 (1-2), pp.16771. 10.1016/j.vetmic.2014.01.024 . pasteur-01104934

\section{HAL Id: pasteur-01104934}

\section{https://hal-pasteur.archives-ouvertes.fr/pasteur-01104934}

Submitted on 12 Mar 2019

HAL is a multi-disciplinary open access archive for the deposit and dissemination of scientific research documents, whether they are published or not. The documents may come from teaching and research institutions in France or abroad, or from public or private research centers.
L'archive ouverte pluridisciplinaire HAL, est destinée au dépôt et à la diffusion de documents scientifiques de niveau recherche, publiés ou non, émanant des établissements d'enseignement et de recherche français ou étrangers, des laboratoires publics ou privés.

\section{(ㄷ)(1)}

Distributed under a Creative Commons Attribution| 4.0 International License 
1 Salmonella serotypes in reptiles and humans, French Guiana

2

3 Noellie Gay ${ }^{1}$, Simon Le Hello $^{2}$, François-Xavier Weill ${ }^{2}$, Benoit de Thoisy ${ }^{3}$, Franck Berger ${ }^{1}$ 4

5 1. Unité d'Épidémiologie, Institut Pasteur de la Guyane, 23 Avenue Pasteur, BP 6010, 97306

6 Cayenne Cedex, French Guiana

7 2. Institut Pasteur, Unité des Bactéries Pathogènes Entériques, Centre National de Référence 8 des Salmonella, 28 rue du Docteur Roux, 75724 Paris Cedex 15, France

9 3. Laboratoire des Interactions Virus-Hôtes, Institut Pasteur de la Guyane, 23 Avenue 10 Pasteur, BP 6010, 97306 Cayenne Cedex, French Guiana

* Corresponding author at: Laboratoire de Recherche et d'Expertise sur la Leptospirose, 13 Institut Pasteur de Nouvelle-Calédonie, Nouméa, Nouvelle-Calédonie. 11 avenue Paul 14 Doumer BP 6198845 Nouméa Cedex. Tel.:+687 2797 46. Fax: +687 2733 90. E-mail address: gnoellie@ hotmail.com or/and ngay@pasteur.nc

Abstract

In French Guiana, a French overseas territory located in the South American northern coast, nearly $50 \%$ of Salmonella serotypes isolated from human infections belong to serotypes rarely encountered in Metropolitan France. A reptilian source of contamination has been

21 investigated. Between April and June 2011, in the area around Cayenne, 151 reptiles were 22 collected: 38 lizards, 37 snakes, 32 turtles, 23 green iguanas and 21 caimans. Cloacal swab samples were collected and cultured. Isolated Salmonella strains were identified

24 biochemically and serotyped. The overall carriage frequency of carriage was $23.2 \%$ (95\% confidence interval: 16.7-30.4) with 23 serotyped strains. The frequency of Salmonella 
carriage was significantly higher for wild reptiles. Near two-thirds of the Salmonella serotypes isolated from reptiles were also isolated from patients in French Guiana. Our results highlight the risk associated with the handling and consumption of reptiles and their role in the spread of Salmonella in the environment.

Key words: Salmonella; reptiles; humans; serotypes; zoonosis; French Guiana

\section{Introduction}

Salmonella is a major foodborne pathogen found worldwide. Non-typhoidal Salmonella causes 93.8 million human cases of gastroenteritis and 155,000 deaths annually worldwide (Majowicz, et al., 2010). The Salmonella genus includes two species: S. enterica and $S$. bongori. S. enterica is subdivided into six subspecies: enterica (former subgenera I), salamae (II), arizonae (IIIa), diarizonae (IIIb), houtenae (IV) and indica (VI). Over 2,600 serotypes were identified according to the White-Kauffmann-Le Minor scheme (Grimont and Weill, 2007). The digestive tract of warm-blooded animals is the main reservoir of Salmonella subspecies enterica (Grimont and Weill, 2007), while other subspecies are mainly found in cold-blooded animals. Reptiles can harbour multiple subspecies and serotypes simultaneously (Pedersen et al., 2009). Most human salmonellosis is associated with eating contaminated raw or undercooked food of animal origin. Other transmission routes exist: human-to-human contacts, consuming contaminated vegetables, water (Wegener et al., 2003) and direct contact with infected animals, including pets. In western countries serotypes from reptiles are rarely encountered in humans (Woodward et al., 1997; O'Byrne and Mahon, 2008). Within the European Union, it is estimated that $<1 \%$ of human salmonellosis are associated with reptiles (Bertrand et al., 2008). Furthermore, serotypes from reptiles seem to be responsible for more severe complications and hospitalizations (Cieslak et al., 1994). 
51 In French Guiana, a French overseas territory (around $85,000 \mathrm{~km}^{2}$ ) located in South America,

52 nearly $50 \%$ of Salmonella isolates from human belong to serotypes rarely encountered in

53 Metropolitan France (Le Hello and Weill, unpublished data).

54 The objectives of this study conducted around Cayenne, the main city of French Guiana, were to assess Salmonella carriage by different reptile species living in different ecosystems (zoo, forest, commensal environment or caged/contained in or around human dwellings) and to compare reptilian and human serotype distributions.

\section{Materials and Methods}

\subsection{Surveillance of human Salmonella infections.}

In France, human Salmonella surveillance is a voluntary laboratory-based network headed by the French National Reference Center for Salmonella (FNRC-Salm). Participating laboratories annually send 8,000-10,000 Salmonella isolates to the FNRC-Salm, which serotypes them and runs weekly outbreak-detection algorithms (David et al., 2011). In 2011, all the medical laboratories from French Guiana (8 private biomedical laboratories and 2 public hospitals) participated to the present study.

67

\subsection{Frequency of Salmonella carriage in reptiles.}

From 5 April to 6 June 2011, reptiles were captured from more-or-less human-occupied environments around Cayenne. Four living conditions were defined: zoo, for captive animals in the zoo; forest, for reptiles captured there; commensal environment, for reptiles living in or around human lodgings (e.g. Hemidactylus mabouia); reptiles caged (e.g., snake terrarium) or

74 private home. 
Cloacal swab samples were collected and kept at room temperature $\left(26 \pm 4^{\circ} \mathrm{C}\right)$ for a maximum of $48 \mathrm{hr}$. Samples were incubated in $9 \mathrm{ml}$ of buffered peptone water for $16-20 \mathrm{hr}$ at $37^{\circ} \mathrm{C}$. Three drops of the pre-enrichment broth were inoculated onto specific medium (Hektoen agar, BioMérieux, Marcy L'Etoile, France) and incubated at $37^{\circ} \mathrm{C}$ for $21-27 \mathrm{hr}$. Lactose-negative colonies were subjected to the urease test and incubated at $37^{\circ} \mathrm{C}$ for $21-27$ hr. When urease was negative (suspected Salmonella), biochemical identification of an isolated colony was pursued with the API 20E Kit (BioMérieux). Isolates were sent to the FNRC-Salm (except subspecies arizonae determined by the API 20E kit) for serotyping according to the White-Kauffmann-Le Minor scheme. All strains underwent antimicrobialsusceptibility testing with the disk-diffusion method on Mueller-Hinton agar (Bio-Rad, Marnes-La-Coquette, France) against 16 antimicrobials (amoxicillin, streptomycin, spectinomycin, azithromycin, kanamycin, netilmicin, amikacin, tobramycin, gentamicin, nalidixic acid, ofloxacin, ciprofloxacin, chloramphenicol, sulfonamides, trimethoprim and tetracycline), according to the guidelines of the French Society for Microbiology (available at: http://www.sfm-microbiologie.org/).

Reptile species were grouped as: caimans, snakes, green iguanas (Iguana iguana), other lizards and turtles. Statistical analyses were computed with Stata ${ }^{\circledR}$ v9.0 Stata Corp; chi $^{2}$ or Fisher's exact tests were used.

\section{Results}

During the study, 151 reptiles (Table 1) were collected. They were distributed in habitats as follows: $34.4 \%$ (52/151) from zoo, 31.8\% (48/151) from forest, $19.9 \%(30 / 151)$ in commensal environment and $13.9 \%(21 / 151)$ caged/contained in or around a private home. 
30.4), ranging between $14.3 \%$ and $32.4 \%$, depending on the type of reptile (Table 1), but did not differ significantly $(\mathrm{p}=0.5)$. Habitat was significantly associated with Salmonella carriage $(\mathrm{p}<0.001)$, with frequencies of $5.8 \%-39.6 \%$. The frequency of carriage was higher for reptiles captured in forests and caged/contained in or around private homes.

S. enterica subspecies represented $47.2 \%$ (17/36) of all isolates (Table 2). Serotyped strains (23/36) belonged to both subspecies enterica $(17 / 23,73.9 \%)$ and houtenae $(6 / 23,26.1 \%)$ and were susceptible to all antibiotics tested. One lizard was co-infected with two enterica subspecies serotypes, Newport and Infantis. Fourteen different serotypes were isolated. The most common serotypes were Anatum $(3 / 23,13.0 \%)$, Rubislaw (13.0\%) and subspecies houtenae serotype 50:g, $\mathrm{Z}_{51}:-(13.0 \%)$. At least three different serotypes were observed for each reptile class except for caimans, which hosted only one.

In 2011, the FNRC-Salm received 154 human Salmonella acquired in French Guiana (87 isolates from Cayenne, 35 from Saint-Laurent-du-Maroni area, 30 from Kourou and two additional from Metropolitan France and Martinique Island, French West Indies). Of the 154, $139(90.3 \%), 14(9.1 \%)$ and $1(0.6 \%)$ belonged, respectively, to enterica, houtenae and diarizonae subspecies (Table 3). Frequently isolated serotypes among enterica subspecies were Panama (18/139, 12.9\%), Oranienburg (11/139, 7.9\%), Saintpaul (11/139, 7.9\%) and Uganda $(10 / 139,7.2 \%)$ and the houtenae subspecies 50:g, $\mathrm{z}_{51}:-$ serotype $(10 / 14,71.4 \%)$.

Among the 14 serotypes isolated from reptiles, $64.3 \%$ were also isolated from humans: Panama, Saintpaul, Uganda, Javiana, Miami, Newport, Rubislaw, Infantis and IV. 50:g,Z51:-.

\section{Discussion}


121 The global frequency of Salmonella carriage by reptiles in the Cayenne area was $23.2 \%$.

122 Salmonella carriage frequency did not differ significantly among groups (caimans, green

123 iguanas, other lizards, snakes and turtles), the highest was documented in snake (32.4\%) and

124 the lowest in Caiman (14.3\%). However, each group is composed of various species; the

125 frequency of carriage might differ depending on the species (Geue and Löschner, 2002).

126 Overall carriage was lower than data obtained from literature. For instance, snake carriage

127 was 32.4\% compared to 45\%-98\% (Sá and Solari, 2001; Geue and Löschner, 2002; Briones et

128 al., 2004; Chen et al., 2010) and green iguana carriage (26.1\%) was lower than 55\%-90\%

129 reported (Mitchell and Shane, 2000; Wheeler et al., 2011). For other lizards, 21.1\% harboured

130 Salmonella, compared to 38-63\% described elsewhere (Sá and Solari, 2001; Geue and

131 Löschner, 2002; Briones et al., 2004; Chen et al., 2010). Difference might be due to the

132 composition of the lizard group, mainly Hemidactylus mabouia (Geue and Löschner, 2002).

133 Turtle carriage (18.8\%) was close to results observed in literature that ranged from 25\% (Sá

134 and Solari, 2001; Briones et al., 2004; Chen et al., 2010) to 80\% (Pasmans et al., 2000;

135 Hidalgo-Vila et al., 2007). Finally, $14.3 \%$ of sampled caimans harboured Salmonella. To our

136 knowledge, only Uhart et al. (2011) reported infection in caimans with fluctuating results

$137(0 \%-77 \%)$ from one year to another.

138 Carriage frequency also differed according to the reptile's habitat. Reptiles captured in the

139 forest had the highest rate $(39.6 \%)$ and zoo dwellers the lowest $(5.8 \%)$. Those observations

140 seem to contradict literature data, as some authors reported higher frequencies (47\%-88.9\%)

141 for zoo-housed reptiles (turtle, snake and lizard) versus $14 \%-58.8 \%$ for their wild counterparts

142 (Geue and Löschner, 2002; Scheelings et al., 2011). That low frequency of carriage among

143 sampled zoo reptiles is difficult to explain as no antibiotics had been administered during the

144 months preceding the study. Indeed, captive conditions should favor inter-individual and

145 interspecies transmission; their captivity and exposure to the general public (e.g. noise) could 
146 be sources of stress, inducing the onset of symptoms and Salmonella excretion (Friendship et

147 al., 2009; Maciel et al., 2010). Salmonella frequency of carriage by reptiles caged/contained

148 in or around private homes was high at $38.1 \%$ which tends to confirm higher frequency of

149 contamination in wild reptiles. All of the latter had been caught in their natural environment

150 and were captive for $<6$ months. A limitation in our study is that each reptile type was not

151 sampled in all habitats, e.g., green iguanas were sampled only at the zoo. However,

152 considering all reptiles sampled, the forest dwellers were, on the whole, fairly well-

153 represented (31.8\%), in contrast to most of studies that focused on captives (Sá and Solari,

154 2001; Pedersen et al., 2009).

155 Comparing our data to those in the literature was difficult as no standard methodology exists

156 for Salmonella isolation from reptiles but globally we could have underestimated frequency of

157 carriage. Cloacal swabbing without enrichment step and use of simplified culture methods

158 mainly target enterica subspecies, the major source of human and animal clinical infections,

159 might underestimate carriage frequencies. We might also have underestimated arizonae and

160 diarizonae subspecies, because respectively, $25 \%$ and $75 \%$ of these subspecies ferment

161 lactose (Grimont and Weill, 2007).

162 Moreover, due to intermittent Salmonella shedding in feces (Bauwens et al., 2006), cloacal

163 swabbing is less sensitive than using digestive tracts from sacrificed animals. However,

164 regulations protecting reptiles restrict it. In addition, only one colony was tested for each

165 animal, consequently coinfection was unlikely. Only one reptile specimen showed multiple

166 infections while reptiles can harbour several Salmonella serotypes simultaneously (Chiodini

167 and Sundberg, 1981).

168 We observed high serotype diversity among reptile samples obtained around Cayenne, with

169 identification of 14 different serotypes among the 23 isolates sent to the FNRC-Salm. At least

170 three different serotypes were isolated from each reptile type (except for caimans which 
171 harboured only one Salmonella serotyped). Lizards exhibited a wide Salmonella diversity,

172 with seven different serotypes found. No patterns of host-specific serotype association were 173 observed, as Briones et al. (2004) claimed. In addition, almost half (47.2\%) of Salmonella

174 isolates belonged to the subspecies enterica, thereby confirming that reptiles serve as

175 reservoirs of this subspecies normally associated with the digestive tract of warm-blooded

176 animals (Geue and Löschner, 2002).

177 In our study, $64.3 \%$ of Salmonella serotypes isolated from reptiles were also isolated from

178 patients in French Guiana. In contrast only 13\% of serotypes isolated were also found in

179 inspected farm chickens (Food, Agriculture and Forestry of French Guiana, unpublished data),

180 it might indicate low environmental contaminations by reptiles. However, no veterinary

181 controls are performed on poultry units producing less than 250 chickens and products are

182 sold directly to consumers. The distribution of Salmonella serotypes could differ in such small

183 poultry farming, as facilities (livestock buildings, granary) are less efficient and interactions

184 with reptiles possibly higher.

185 Thus, reptiles might be the direct or indirect source of a high percentage of human Salmonella

186 infections in French Guiana.

187

188 5. Conclusion

189 Reptiles are Salmonella reservoirs and might represent public health risk, especially in French

190 Guiana, where a huge diversity of reptile species is observed and some in close contact with

191 humans (Hemidactylus mabouia having ready access into homes...) and probably livestock.

192 Furthermore, they represent food sources, particularly green iguanas. Therefore, hygiene

193 measures concerning the handling of reptiles, cooking their meat and cleaning kitchen utensils

194 should be promoted. 
197 We declare that we have no conflicts of interest.

\section{Authors contributions}

199 FB conceived and designed the experiments. NG and BDT collected data. NG performed the 200 experiments. SLH, FXW provided data from humans. NG, FB analyzed the data. NG wrote 201 the paper. SLH, FXW and BDT reviewed, criticised and offered comments on the text.

\section{Acknowledgments}

204 Daniel Lanfranchi, Laboratory Health and Environment, for his availability and advice regarding the simplified laboratory protocol for Salmonella identification; Leon

Razafindrakoto, Curator of the Kaw Reserve, and Olivier Bongard, Director of the Zoo of

French Guiana, who allowed us to collect samples and Sylvie Baillargeaux who obtained

208 cloacal samples. This study was supported by Institut Pasteur and Institut Pasteur de la

209 Guyane.

\section{References}

Bauwens, L., Vercammen, F., Bertrand, S., Collard, J.M., De Ceuster, S., 2006. Isolation of Salmonella from environmental samples collected in the reptile department of Antwerp Zoo using different selective methods. J. Applied Microbiol. 101, 284-289.

Bertrand, S., Rimhanen-Finne, R., Weill, F.X., Rabsch, W., Thornton, L., Perevoscikovs, J., Perevoscikovs, J., van Pelt, W., Heck, M., 2008. Salmonella infections associated with reptiles: the current situation in Europe. Euro Surveill. 13, 1-6.

Briones, V., Téllez, S., Goyache, J., Ballesteros, C., del Pilar Lanzarot, M., Domínguez, L., Fernández-Garayzábal, J.F., 2004. Salmonella diversity associated with wild reptiles and amphibians in Spain. Environ. Microbiol. 6, 868-871. 
Chen, C.Y., Chen, W.C., Chin, S.C., Lai, Y.H., Tung, K.C., Chiou, C.S., Hsu, Y.M., Chang, C.C., 2010. Prevalence and antimicrobial susceptibility of Salmonella isolates from reptiles in Taiwan. J. Vet. Diagn. Invest. 22, 44-50.

Chiodini, R.J., Sundberg, J.P., 1981. Salmonellosis in reptiles: a review. Am. J. Epidemiol. $113,494-499$.

Cieslak, P.R., Angulo, F.J., Dueger, E.L., Maloney, E.K., Swerdlow, D.L., 1994. Leapin' lizards: a jump in the incidence of reptile-associated salmonellosis. In: Program and abstracts of the $34^{\text {th }}$ Interscience Conference on Antimicrobial Agents and Chemotherapy, American Society for Microbiology, Washington DC, pp 270.

David, J., Danan, C., Chauvin, C., Chazel, M., Souillard, R., Brisabois, A., Weill, FX., Jourdan-Da Silva, N., Picherot, M., Guillemot, D., Sanders, P., 2011. Structure of the French farm-to-table surveillance system for Salmonella. Revue Méd. Vét. 10, 489-500.

Friendship, R.M., Mounchili, A., McEwen, S., Rajic, A., 2009. Critical review of on-farm intervention strategies against Salmonella. Available at: http://www.bpex.org/downloads/298614/292327/Critical\%20review\%20of\%20onfarm\%2 Ointe. Accessed September 2, 2013.

Geue, L., Löschner, U., 2002. Salmonella enterica in reptiles of German and Austrian origin. Vet. Microbiol. 84, 79-91.

Grimont, P.A.D., Weill, F.X., 2007. Antigenic formulae of the Salmonella serovars, 9th (Eds.). WHO. Collaborating Center for Reference and Research on Salmonella, Institut Pasteur, Paris, France.

Hidalgo-Vila, J., Díaz-Paniagua, C., De Frutos-Escobar, C., Jiménez-Martínez, C., PérezSantigosa, N., 2007. Salmonella in free living terrestrial and aquatic turtles. Vet. Microbiol. 119, 311-315.

Jourdan-Da Silva, N., Le Hello, S., 2012. Salmonelloses en France, 2002-2010: tendances en 
épidémiologie humaine, émergence de la souche monophasique, principaux aliments impliqués dans les dernières épidémies. B.E.H. Hors-série 25-28.

Maciel, B.M., Argôlo Filho, R.C., Nogueira, S.C., Dias, J.C.T., Rezende, R.P., 2010. High prevalence of Salmonella in tegu lizards (Tupinambis merianae), and susceptibility of the serotypes to antibiotics. Zoonoses Public Health 57, 26-32.

Majowicz, S.E., Musto, J., Scallan, E., Angulo, F.J., Kirk, M., O'Brien, S.J., Jones ,T.F., Fazil, A., Hoekstra, R.M., 2010. The global burden of nontyphoidal Salmonella gastroenteritis. Clin. Infect. Dis. 50, 882-889.

Mitchell, M.A., Shane, S.M., 2000. Preliminary findings of Salmonella spp. in captive green iguanas (Iguana iguana) and their environment. Prev. Vet. Med. 45, 297-304.

O'Byrne, A.M., Mahon, M., 2008. Reptile-associated Salmonellosis in residents in the South East of Ireland 2005-2007. Euro. Surveill. 13, 1-2.

Pasmans, F., De Herdt, P., Chasseur-Libotte, M.L., Ballasina, D.L.P., Haesebrouck, F., 2000. Occurrence of Salmonella in tortoises in a rescue centre in Italy. Vet. Rec. 146, 256-258.

Pedersen, K., Lassen-Nielsen, A.M., Nordentoft, S., Hammer, A.S., 2009. Serovars of Salmonella from captive reptiles. Zoonoses Public Health 56, 238-242.

Sá, I.V.A., Solari, C.A., 2001. Salmonella in Brazilian and imported pet reptiles. Brazilian J. Microbiol. 32, 293-297.

Scheelings, T.F., Lightfoot, D., Holtz, P., 2011. Prevalence of Salmonella in Australian reptiles. J. Wildl. Dis. 47, 1-11.

Uhart, M., Ferreyra, H., Mattiello, R., Caffer, M.I., Terragno, R., Schettino, A., Prado, W., 2011. Isolation of Salmonella spp. from yacare caiman (Caiman yacare) and broadsnouted caiman (Caiman latirostris) from the Argentine Chaco. J. Wildl. Dis. 47, 271277.

270 Wegener, H.C., Hald, T., Lo Fo Wong, D., Madsen, M., Korsgaard, H., Bager, F., Gerner- 
Smidt, P., Mølbak, K., 2003. Salmonella control programs in Denmark. Emerg. Infect. Dis. 9, 774-780.

273

Wheeler, E., Cann, I.K.O., Mackie, R.I., 2011. Genomic fingerprinting and serotyping of Salmonella from Galápagos iguanas demonstrates island differences in strain diversity. Environ. Microbiol. Rep. 3, 166-173.

Woodward, D.L., Khakhria, R., Johnson, W.M., 1997. Human salmonellosis associated with exotic pets. J. Clin. Microbiol. 35, 2786-2790.

Author's current address:

Noellie Gay, Unité de Recherche et d'Expertise sur la Leptospirose, Institut Pasteur de

Nouvelle-Calédonie, Nouméa, Nouvelle-Calédonie, E-mails: ngay@pasteur.nc and gnoellie@hotmail.com. Simon Le Hello, Unité des Bactéries Pathogènes Entériques, Centre National de Référence des Salmonella, Institut Pasteur, Paris, France, E-mail:

slehello@pasteur.fr. François-Xavier Weill, Unité des Bactéries Pathogènes Entériques, Centre National de Référence des Salmonella, Institut Pasteur, Paris, France, Email:

fxweill@pasteur.fr. Benoit de Thoisy, Laboratoire des Interactions Virus-Hôtes, Institut Pasteur de la Guyane, Cayenne, French Guiana, Email: bdethoisy@ pasteur-cayenne.fr. Franck Berger, Centre d'Épidémiologie et de Santé Publique des Armées, Marseille, France, Email: franckdesp@gmail.com. 


\section{TABLES}

\section{Table 1}

Reptile Salmonella carriage according to reptile type or living conditions

\begin{tabular}{|c|c|c|c|c|c|}
\hline Parameter & $\mathrm{N}(\%)$ & Sal & nonella frequency & $\mathrm{p}$ & OR $[95 \% \mathrm{CI}]$ \\
\hline & & $\mathrm{n}$ & $\%(95 \% \mathrm{CI})$ & & \\
\hline Reptile & & & & 0.5 & \\
\hline Caimans & $21(13.9)$ & 3 & $14.3(3.0-36.3)$ & & 1.0 \\
\hline Turtles & $32(21.2)$ & 6 & $18.8(7.2-36.4)$ & & $1.4[0.3-6.3]$ \\
\hline Green Iguanas & $23(15.2)$ & 6 & $26.1(10.2-48.4)$ & & $2.1[0.5-9.8]$ \\
\hline Other lizards & $38(25.2)$ & 8 & $21.1(9.6-37.3)$ & & $1.6[0.4-6.8]$ \\
\hline Snakes & $37(24.5)$ & 12 & $32.4(18.0-49.8)$ & & $2.9[0.7-11.7]$ \\
\hline Total & $151(100)$ & 35 & $23.2(16.7-30.4)$ & & \\
\hline Living Conditions & & & & $<0.001$ & \\
\hline Zoo & $52(34.4)$ & 3 & $5.8(1.2-15.9)$ & & 1.0 \\
\hline Commensal environment & $30(19.9)$ & 5 & $16.7(5.6-34.7)$ & & $3.3[0.7-15.1]$ \\
\hline Caged/Contained & $21(13.9)$ & 8 & $38.1(18.1-61.6)$ & & $10.3[2.4-44.2]$ \\
\hline Forest & $48(31.8)$ & 19 & $39.6(25.8-54.7)$ & & $11.3[3.1-41.6]$ \\
\hline Total & $151(100)$ & 35 & $23.2(16.7-30.4)$ & & \\
\hline
\end{tabular}




\section{TABLE 2}

Distribution of S. enterica subspecies among sampled reptiles

\begin{tabular}{lccc}
\hline Subspecies & Isolates N (\%) & Salmonella serotyped & $\%(95 \%$ CI) \\
\hline arizonae (IIIa) & $13(36.1)$ & 0 & $36.1(20.8-53.8)$ \\
enterica* $^{(I)}$ & $17(47.2)$ & 17 & $47.2(30.4-64.5)$ \\
houtenae (IV) & $6(16.7)$ & 6 & $16.7(6.4-32.8)$ \\
Total & $36(100)$ & 23 &
\end{tabular}

*Two serotypes in one reptile sample. 
TABLE 3

Salmonella serotypes isolated from humans in French Guiana in 2011

Metropolitan

$$
\text { French Guiana }(\mathrm{n}=154)^{*} \quad \text { France }
$$

Serotype

$$
(\mathrm{n}=7,521)
$$

Cumulated

\begin{tabular}{|c|c|c|c|c|c|}
\hline enterica (I) subspecies & 139 & 90.3 & & 7,401 & 98.4 \\
\hline Panama & 18 & 12.9 & 12.9 & 36 & 0.5 \\
\hline Oranienburg & 11 & 7.9 & 20.8 & 23 & 0.3 \\
\hline Saintpaul & 11 & 7.9 & 28.7 & 61 & 0.8 \\
\hline Uganda & 10 & 7.2 & 35.9 & 3 & 0.04 \\
\hline Javiana & 8 & 5.8 & 41.7 & 8 & 0.1 \\
\hline Miami & 8 & 5.8 & 47.4 & 5 & 0.07 \\
\hline Newport & 8 & 5.8 & 53.2 & 110 & 1.5 \\
\hline Enteritidis & 7 & 5.0 & 58.2 & 1,075 & 14.5 \\
\hline Poona & 7 & 5.0 & 63.3 & 35 & 0.5 \\
\hline Rubislaw & 7 & 5.0 & 68.3 & 4 & 0.05 \\
\hline Typhi & 4 & 2.9 & 71.2 & 43 & 0.6 \\
\hline Arechavaleta & 4 & 2.9 & 74.1 & 2 & 0.03 \\
\hline$\underline{1}, 4,[5], 12: \mathrm{i}:-$ & 3 & 2.2 & 76.2 & 2,084 & 28.2 \\
\hline Morehead & 3 & 2.2 & 78.4 & 0 & 0 \\
\hline $9,12:-: 1,5$ & 2 & 1.4 & 79.8 & 2 & 0.03 \\
\hline Belem & 2 & 1.4 & 81.2 & 0 & 0 \\
\hline Chester & 2 & 1.4 & 82.7 & 22 & 0.3 \\
\hline
\end{tabular}

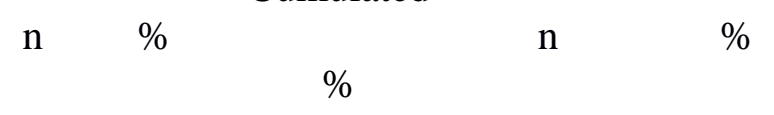




\begin{tabular}{|c|c|c|c|c|c|}
\hline Coeln & 2 & 1.4 & 84.1 & 13 & 0.2 \\
\hline Infantis & 2 & 1.4 & 85.6 & 150 & 2.0 \\
\hline Itami & 2 & 1.4 & 87.0 & 1 & 0.01 \\
\hline Jukestown & 2 & 1.4 & 88.4 & 0 & 0 \\
\hline Kentucky & 2 & 1.4 & 89.9 & 115 & 1.6 \\
\hline Typhimurium & 2 & 1.4 & 91.3 & 1,843 & 24.9 \\
\hline Weltevreden & 2 & 1.4 & 92.8 & 20 & 0.3 \\
\hline Rough & 1 & 0.7 & 93.5 & 18 & 0.2 \\
\hline Agona & 1 & 0.7 & 94.2 & 43 & 0.6 \\
\hline Claibornei & 1 & 0.7 & 94.9 & 1 & 0.01 \\
\hline Manhattan & 1 & 0.7 & 95.6 & 6 & 0.08 \\
\hline Oslo & 1 & 0.7 & 96.4 & 0 & 0 \\
\hline Paratyphi B dT+ (biotype Java) & 1 & 0.7 & 97.1 & 20 & 0.3 \\
\hline Sandiego & 1 & 0.7 & 97.8 & 3 & 0.04 \\
\hline Senftenberg & 1 & 0.7 & 98.5 & 16 & 0.2 \\
\hline Telelkebir & 1 & 0.7 & 99.2 & 5 & 0.07 \\
\hline Thompson & 1 & 0.7 & 100.0 & 11 & 0.1 \\
\hline diarizonae (IIIb) subspecies & 1 & 0.6 & & 33 & 0.4 \\
\hline 17:z10:e,n,x,z15 & 1 & 100.0 & 100.0 & 0 & 0 \\
\hline houtenae (IV) subspecies & 14 & 9.1 & & 22 & 0.3 \\
\hline 50:g,z51:- & 10 & 71.4 & 71.4 & 4 & 18.2 \\
\hline 44:z4,z24:- & 2 & 14.3 & 85.7 & 0 & 0 \\
\hline 11:g,z51:- & 1 & 7.1 & 92.9 & 0 & 0 \\
\hline Rough & 1 & 7.1 & 100.0 & 0 & 0 \\
\hline
\end{tabular}

*One per patient. 